\title{
spe $A$ and speC toxin genes among group A streptococcus isolates from school children in Chennai, India
}

Streptococcus pyogenes or group A streptococci (GAS) have been frequently reported in recent years from invasive infections and toxic shock-like syndrome (TSLS) (Peter et al., 1993; Dhawan et al., 2002). TSLS is precipitated by strains producing streptococcal pyrogenic exotoxins (SPE toxins), which are superantigens. They cause the release of massive amounts of cytokines, mediating overwhelming inflammatory responses (Roggiani et al., 2000). Streptococcal toxic shock has a $30 \%$ mortality rate (Hauser et al., 1991). The speB gene is chromosomally encoded (Chaussee et al., 1996), whereas the exotoxin-encoding genes speA and $s p e C$ are carried by lysogenic phages, and are easily disseminated to other GAS (Sriskandan et al., 2000).

Most studies are focused on screening GAS isolates from patients with TSLS, invasive infections or community outbreaks for SPE toxins. The aim of this study was to screen GAS obtained from a community surveillance programme for speA, $B$ and $C$ toxin-encoding genes.

A total of 116 GAS strains that comprised 60 carrier, 32 tonsillitis and 24 pyoderma isolates obtained from a school surveillance programme for GAS were included in this study. Standard GAS strains carrying speA, $B$ and $C$ toxinencoding genes were kindly gifted by $\mathrm{Dr}$ K. N. Brahmadathan, CMC, Vellore, India. DNA was extracted from fresh subcultures of GAS by alkali lysis (Hartas et al., 1998). spe $A, B$ and $C$ detection was performed by multiplex PCR (Miyoshi-Akiyama et al., 2003) with minor modifications. The $25 \mu \mathrm{l}$ PCR mixture contained $5 \mu$ template DNA, $1 \mu \mathrm{M}$ each primer, $200 \mu \mathrm{M}$ dNTPs and $5 \mathrm{U} \mathrm{Taq}$ polymerase (Supratherm) in Taq buffer. The PCR conditions were as follows: 1 cycle at $95{ }^{\circ} \mathrm{C}$ for $1 \mathrm{~min} ; 30$ cycles of denaturation at $93{ }^{\circ} \mathrm{C}$ for $30 \mathrm{~s}$, annealing at $57{ }^{\circ} \mathrm{C}$ for $30 \mathrm{~s}$, and extension at $72{ }^{\circ} \mathrm{C}$ for $1 \mathrm{~min}$; and 1 extension cycle at $72{ }^{\circ} \mathrm{C}$ for $3 \mathrm{~min}$. Gel electrophoresis was performed using $2 \%$ agarose. The size of the PCR products of speB was $1113 \mathrm{bp}$, speA was $393 \mathrm{bp}$ and speC was $540 \mathrm{bp}$. All strains were screened for in vitro production of cysteine proteinase (SpeB) by a caseinolytic assay (Hynes \& Tagg 1985) to correlate with speB detection.

The phage gene-encoded toxins speA and speC were present in $8 \%(9 / 116)$ and $17 \%$ $(20 / 116)$ of the GAS strains screened. None of the strains had both speA and speC. Among the 60 carrier strains obtained from asymptomatic school children, speA could be demonstrated in $7 \%(4 / 60)$ and speC in $22 \%(13 / 60)$ of the strains. Among the 32 tonsillitis GAS strains, only $3 \%$ (1/32) were positive for speA and $9 \%$ (3/32) were positive for speC. One pyoderma strain $(1 / 24,4 \%)$ had the speA gene, and four pyoderma strains $(4 / 24$, $17 \%$ ) had the speC gene. The gene speB was present in all strains (100\%) screened. Of the 116 strains tested for extra-cellular production of cysteine proteinase, only $46 \%(53 / 116)$ of the strains ( 28 carrier, 16 tonsillitis and 9 pyoderma strains) were positive.

Screening for speA and speC is done in outbreaks and for patients admitted with toxic shock. Though the speB gene is present in all GAS, expression of cysteine proteinase, which is associated with tissue damage and shock, is variable (Chaussee et al., 1996). In this study, the presence of toxigenic-strain carriers in the normal population, particularly among school children, is alarming, as they can operate as reservoirs of potentially invasive GAS. An outbreak of speA positive GAS in a school has been documented (Cockerill et al., 1997). There is also a report of toxigenic GAS carriage in a hospital setting (Ekelund et al., 2005). Given that GAS carriers can transmit $9 \%$ of the time, and that those with symptomatic infection can transmit $25 \%$ of the time (Pichichero \& Casey 2003), the high percentage of toxigenic GAS in our study spells the possibility of an outbreak in a crowded school setting. Furthermore, spe $A$ and $C$ can be mobilized by lysogenic phages into non-toxic strains, facilitating dissemination of toxigenicity. Children from poor economic backgrounds rarely seek medical attention for throat and skin infections, unless severe, and hence are at a risk of developing TSLS, when colonized or infected with toxigenic GAS. Of interest in this study, was that the carrier isolates had a higher percentage of $s p e A, s p e C$ and extracellular cysteine proteinase production when compared with those isolated from throat and skin infections, which emphasizes the importance of identifying and treating the carrier status.

\section{Acknowledgements}

The authors gratefully acknowledge funding from CSIR, India, in the form of a Senior Research Fellowship (SRF). The authors thank Dr K. N. Brahmadathan, CMC, Vellore, India, for kindly gifting us standard toxigenic GAS strains, and Dr Tohru Miyoshi-Akiyama, International Medical Centre of Japan, for her technical advice.

\section{Charmaine Lloyd and Thangam Menon}

Department of Microbiology, Dr A. L. Mudaliar Post Graduate Institute of Basic Medical Sciences, University of Madras, Taramani, Chennai 600113, Tamil Nadu, India.

\section{Correspondence: Thangam Menon (thangam16@rediffmail.com)}

\section{References}

Chaussee, M. S., Liu, J., Stevens, D. L. \& Ferretti, J. J. (1996). Genetic and phenotypic diversity among isolates of Streptococcus pyogenes from invasive infections. J Infect Dis 173, 901-908.

Cockerill, F. R., III, MacDonald, K. L., Thompson, R. L., Roberson, T. F., Kohner, P. C., Besser-Wiek, J., Manahan, J. M., Musser, J. M., Schlievert, P. M. \& other authors (1997). An outbreak of invasive group A streptococcal 
disease associated with high carriage rates of the invasive clone among school-aged children. JAMA 277, 38-43.

Dhawan, B., Mohanty, S., Ammini, A. C., Dhanwal, D., Das, B. K. \& Kapil, A. (2002). Streptococcal toxic shock syndrome. J Assoc Physicians India 50, 599-600.

Ekelund, K., Darenberg, J., Norrby-Teglund, A., Hoffmann, S., Bang, D., Skinhøj, P. \& Konradsen, H. B. (2005). Variations in emm type among group A streptococcal isolates causing invasive or non-invasive infections in a nationwide study. J Clin Microbiol 43, 3101-3109.

Hartas, J., Hibble, M. \& Sriprakash, K. S. (1998). Simplification of a locus-specific DNA typing method (Vir typing) for Streptococcus pyogenes. J Clin Microbiol 36, 1428-1429.
Hauser, A. R., Stevens, D. L., Kaplan, E. L. \& Schlievert, P. M. (1991). Molecular analysis of pyrogenic exotoxins from Streptococcus pyogenes isolates associated with toxic shock-like syndrome. J Clin Microbiol 29, 1562-1567.

Hynes, W. L. \& Tagg, J. R. (1985). A simple plate assay for detection of group A streptococcal proteinase. J Microbiol Methods 4, 25-31.

Miyoshi-Akiyama, T., Zhao, J., Kikuchi, K., Kato, H., Suzuki, R., Endoh, M. \& Uchiyama, T. (2003). Quantitative and qualitative comparison of virulence traits, including murine lethality, among different $\mathrm{M}$ types of group A streptococci. J Infect Dis 187, 18761887.

Peter, J. V., Abraham, O. C., George, S., Brahmadathan, K. N. \& Mathai, D. (1993). Toxic strep syndrome. J Assoc Physicians India 41, 175-176.

Pichichero, M. E. \& Casey, J. R. (2003). Defining and dealing with carriers of group A streptococci. Contemp Pediatr 20, 46-56.

Roggiani, M., Stoehr, J. A., Olmsted, S. B., Matsuka, Y. V., Pillai, S., Ohlendorf, D. H. \& Schlievert, P. M. (2000). Toxoids of streptococcal pyrogenic exotoxin A are protective in rabbit models of streptococcal toxic shock syndrome. Infect Immun 68, 50115017.

Sriskandan, S., Unnikrishnan, M., Krausz, T. \& Cohen, J. (2000). Mitogenic factor (MF) is the major DNase of serotype M89 Streptococcus pyogenes. Microbiology 146, 2785-2792. 